\title{
The Effect of a Metamaterial Based Wearable Monopole Antenna on the Human Body
}

\author{
Erkan Tetik ${ }^{1 *}$, Gamze D. Tetik ${ }^{2}$ \\ ${ }^{1}$ Computer Education and Instructional Technology, Faculty of Education, Usak University, Usak, Turkey, \\ 5375952953, erkan.tetik@usak.edu.tr \\ ${ }^{2}$ Materials Science and Nanotechnology Engineering, Faculty of Engineering, Usak University, Usak, Turkey, \\ 5052164238, gamze.tetik@usak.edu.tr \\ *Corresponding Author
}

Received: 20 December 2017

Accepted: 13 March 2018

DOI: $10.18466 /$ cbayarfbe.369051

\begin{abstract}
In this study, design and characterization of a wearable monopole antenna and metamaterial based electromagnetic band gap structure using conductive textile was reported. The pure copper polyester taffeta fabric was used as a conductive textile. The conductive textile based wearable antennas have attracted considerable attention for body centric technologies due to the ability of being integrated with clothes and easily worn. In this respect, the reflection coefficients, radiation pattern, and surface currents for proposed antenna were investigated and its performance was obtained. Then, we designed the electromagnetic band gap structure (3x3 unit cell) and integrated the wearable antenna with this structure. Finally, the specific absorption rate (SAR) values for wearable antenna and integrated structure were analyzed. The SAR values of wearable antenna and integrated structure were obtained as $17.4 \mathrm{~W} / \mathrm{kg}$ and $0.329 \mathrm{~W} / \mathrm{kg}$, respectively. In addition, the electromagnetic band gap structure that has $4 \times 3$ unit cell was designed and again the wearable antenna was integrated with this $4 \times 3$ structure. Similarly, we obtained the SAR value of new integrated structure as 0.241 $\mathrm{W} / \mathrm{kg}$. It was demonstrated that the integrated structures have considerably favorable SAR value for human body. It can be used in many wearable antenna applications with this low SAR value.
\end{abstract}

Keywords: Wearable Antenna, Metamaterial, Conductive Textile Materials, SAR

\section{Introduction}

In the recent years, the electro-textile materials have attracted considerable attention because they can be potentially applied in the areas such as electronic, health monitoring, telecommunication, and textile sciences. The body centric wireless communication which is one of their application areas can be described the link between body mounted devices communicating wirelessly [1]. This body communication is accepted as an important part of fourth generation mobile communication systems (4G) [2] and is mostly provided by wearable devices. A big part of these wearable devices consists of the fabricbased antennas. Wearable antennas, which are known as electro-textile antenna devices, has many related attractive features such as low profile, low weight, and washability. In addition, these devices can be easily integrated within everyday clothing. Therefore, their use in daily life is of interest to researchers and there have been many investigations with the wearable electrotextile antennas $[3,4]$. In this context, the researches have shown that the wearable antennas have some requirements to be flexible [5, 6]. In addition, they should provide low and stable resistivity that should be less than
$1 \mathrm{ohm} / \mathrm{sq}$. These antennas consist of an intermediate substrate which is made up of material such as felt [5], cotton [7], flannel fabric [8] or jeans [9]. In the structure of these antennas, the conductive materials like the pure copper polyester taffeta fabric are used.

The electro-textile based designs have been reported as single frequency band wearable antennas $[10,11]$. In addition, in some studies, the design of the single frequency electromagnetic band gap (EBG) material based antennas have been reported [12]. The recent interest in field of electromagnetic wave engineering is on metamaterial (MTM) technology [13]. EBG structure is one of the MTMs with the property to suppress electromagnetic wave propagation in a certain frequency band. MTMs which have unusual properties that are not easily found in nature are defined as artificial electromagnetic structures. They are used in many different applications such as sensors [14], superlens [15], cloaking [16], and harvesting [17]. Commonly used EBG structures can be listed as the mushroom and vialess EBG Structures. These structures can be integrated into the wearable antennas and have the feature of 
reducing the backward radiation from the antenna $[18$, 19]. In this sense, one of the most important issues about wearable antennas is the closeness of human body to antennas. The human body may be exposed to antenna radiation at close range, and it may be negatively affected owing to the amount of power absorbed per unit mass of the body. Here, the specific absorption rate (SAR) is measured as the exposure of power absorbed per unit mass of human body. American National Standards Institute (ANSI) has set the limit of $1.6 \mathrm{~W} / \mathrm{Kg}$ absorbed per $1 \mathrm{~g}$ of tissue and $2 \mathrm{~W} / \mathrm{Kg}$ absorbed per $10 \mathrm{~g}$ of tissue.

In this study, the wearable antenna that can operate at $2.45 \mathrm{GHz}$ was designed and investigated the reflection coefficients, radiation pattern, and SAR value. The SAR value of the proposed antenna is evaluated on a cylindrical human tissue model. Then, the EBG structure that can operate at $2.45 \mathrm{GHz}$ was designed. The SAR value of integrated wearable antenna and EBG structure was obtained. According to the results obtained, we evaluated the effects of SAR value of the wearable antenna and integrated structure on human body.

\section{Design of the Wearable Antenna and EBG Structure}

The electro-textile materials are important devices for wearable antenna technology. These materials are composed of the conductive fabrics [20] that are obtained by interleaving normal fabrics with conductive metal/polymer threads. In this study, pure copper polyester taffeta fabric (PCPTF) was used as conductor material. The measured resistance, electrical conductivity and surface resistance of PCPTF are 0.031 $\mathrm{Ohm} / \mathrm{sq}, 2.5 \times 105 \mathrm{~S} / \mathrm{m}$ and $0.05 \mathrm{Ohm} / \mathrm{sq}$, respectively [9]. In addition, the felt textile material was used as the substrate of antenna. The loss tangent, permittivity and thickness of the felt material are 0.016, 1.22 and $2 \mathrm{~mm}$, respectively. There are many types of wearable antennas and they are used in various applications. Several types of wearable antennas have been proposed with different topologies, e.g., patch antennas, planar antennas and monopole antennas. In this study, wearable monopole antenna design was chosen. The geometry of wearable monopole antenna is shown in Figure 1. The patch of antenna was made up with PCPTF material, the substrate and ground plane of antenna were made up with Felt materials in the design. The proposed wearable antenna which has sizes of $40 \times 60 \mathrm{~mm}$ consists of 3 parts as ground plane, substrate, and patch. The substrate has a thickness of $2 \mathrm{~mm}$ and sizes of $40 \times 14 \mathrm{~mm}$. The patch has a thickness of $0.8 \mathrm{~mm}$ and sizes $8.5 \times 42.8 \mathrm{~mm}$.
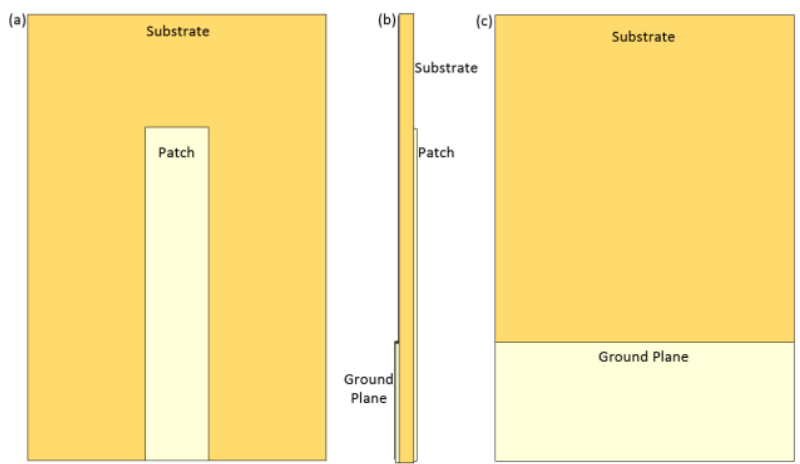

Figure 1 The electro-textile based wearable monopole antenna design. (a) The front view, (b) left view, and (c) back view.

Then, we designed the mushroom based EBG structure and integrated the proposed wearable antenna and EBG structure. The geometry of proposed EBG structure is shown in Figure 2. The EBG structure which is also designed using electro-textile materials consists of the PCPTF and felt structures. Thus, the whole of proposed integrated structure has the features of wearable materials. The proposed wearable EBG structure which has sizes of $48 \times 48 \mathrm{~mm}$ consists of 3 parts as ground plane, substrate, and patch. The ground plane and patch has a thickness of $0.08 \mathrm{~mm}$. The patch of EBG structure has sized $46 \times 46 \mathrm{~mm}$. the thickness of substrate is 1.1 $\mathrm{mm}$. In addition, this structure has a via structure that is located in its center. The radius of the via is $0.5 \mathrm{~mm}$. The EBG structure was integrated in the bottom of the antenna.

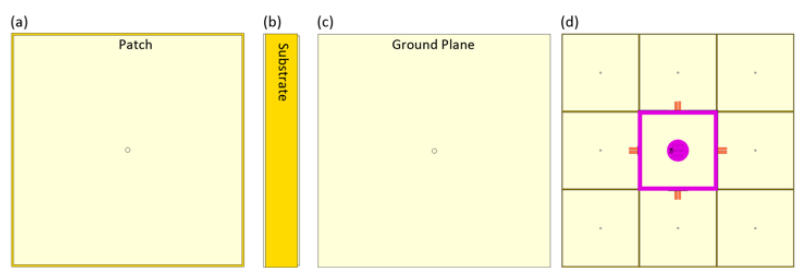

Figure 2 The unit cell of electro-textile based EBG design. (a) The front view, (b) left view, (c) back view, and (d) $3 \times 3$ EBG structure.

\section{Calculation Method, Results, and Discussion}

We simulated the properties of the wearable antenna structures using FIT (Finite Integration Technique) based a full-wave electromagnetic solver CST Microwave Studio. The proposed wearable antenna consists of the integration of monopole antenna and EBG structure. After designing the proposed antenna and EBG structure, numerical calculations are realized to obtain the properties of $\mathrm{S}$ parameters and surface currents of the model. The simulation studies of the proposed structure are carried out at $0-4 \mathrm{GHz}$ frequency range. The $\mathrm{S}$ parameter results obtained from the antenna calculations are given in Figure 3a. 


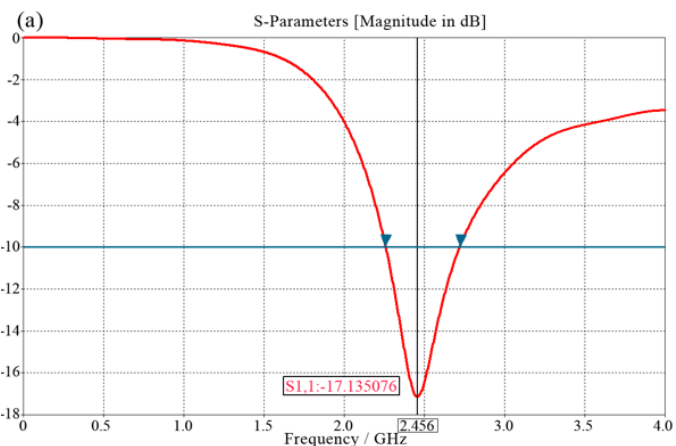

(b)

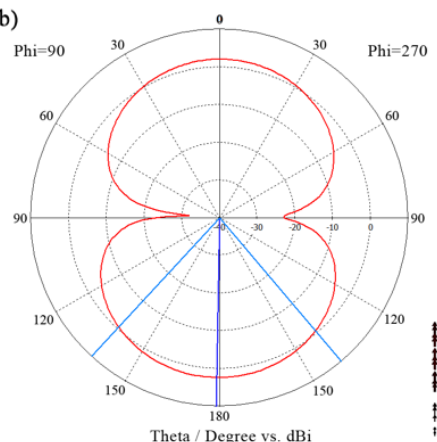

(c)

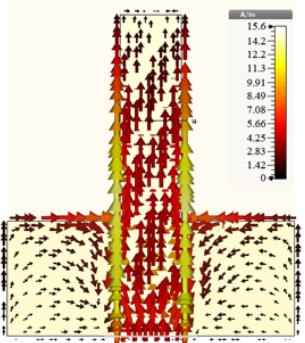

Figure 3 (a) The simulated reflection coefficient $\left(S_{11}\right)$, (b) radiation pattern, and (c) surface currents of the wearable monopole antenna.

We investigated the performance of the wearable monopole antenna that operates in the $2.45 \mathrm{GHz}$ industrial, scientific and medical (ISM) band. Proposed antenna reflects at a frequency of $2.45 \mathrm{GHz}$ and has a good propagation at this frequency. It means that, this antenna works efficiently at the frequency of $2.45 \mathrm{GHz}$. The normalized radiation pattern of the proposed antenna depicted in Figure $3 \mathrm{~b}$ at $2.45 \mathrm{GHz}$. The radiation pattern is omnidirectional in azimuth plane with a maximum gain of $2.34 \mathrm{dBi}$ at $2.45 \mathrm{GHz}$. This novel electro-textile based monopole antenna can be efficiently used in wearable applications where textile technologies are the main requirement. To examine the performance and distribution of proposed antenna, we obtained the surface currents at $2.45 \mathrm{GHz}$ that is demonstrated in Figure 3c. The antenna propagation in the middle parts is adequate and well done. In addition, we obtained the bandwidth values of the proposed monopole antenna between the triangle points at the $-10 \mathrm{~dB}$ line. The first and second triangle points have $2.2576 \mathrm{GHz}$ and $2.7196 \mathrm{GHz}$ values. In this case, the bandwidth value of this antenna is 0.4620 (2.7196-2.2576) GHz (462 MHz). According to the results obtained, textile based monopole antenna can be easily used in industrial applications due to its geometry and frequency band.

In the maximum frequency value of the absorption $A(\omega)$ of the MTM structures, the transmission $T(\omega)$ and the reflection $R(\omega)$ minimize simultaneously. In this way, electromagnetic wave absorption with respect to frequency is determined by $A(\omega)=1-R(\omega)-T(\omega)$ formula with $R(\omega)=\left|S_{11}\right|^{2}$ and $T(\omega)=\left|S_{21}\right|^{2}$. Due to the equations $\left|S_{21}\right|^{2}=0$ and $T(\omega) \rightarrow 0$, the absorption equation is defined as $A(\omega)=1-R(\omega)$. According to this, the absorption, transmission, and reflection results of the proposed structure are shown in Figure 4a. The EBG structure shows maximum absorption of $99.39 \%$ at the $2.4566 \mathrm{GHz}$ resonance frequency. Hence, it is understood that the EBG structure has the ability to suppress the electromagnetic wave generated by the antenna at $2.456 \mathrm{GHz}$ frequency. In addition, the real and imaginary part of permittivity is demonstrated in Figure 4b. In this, case, the proposed EBG structure has MTM characteristic because the reel part of permittivity has the negative value in the resonance frequency.

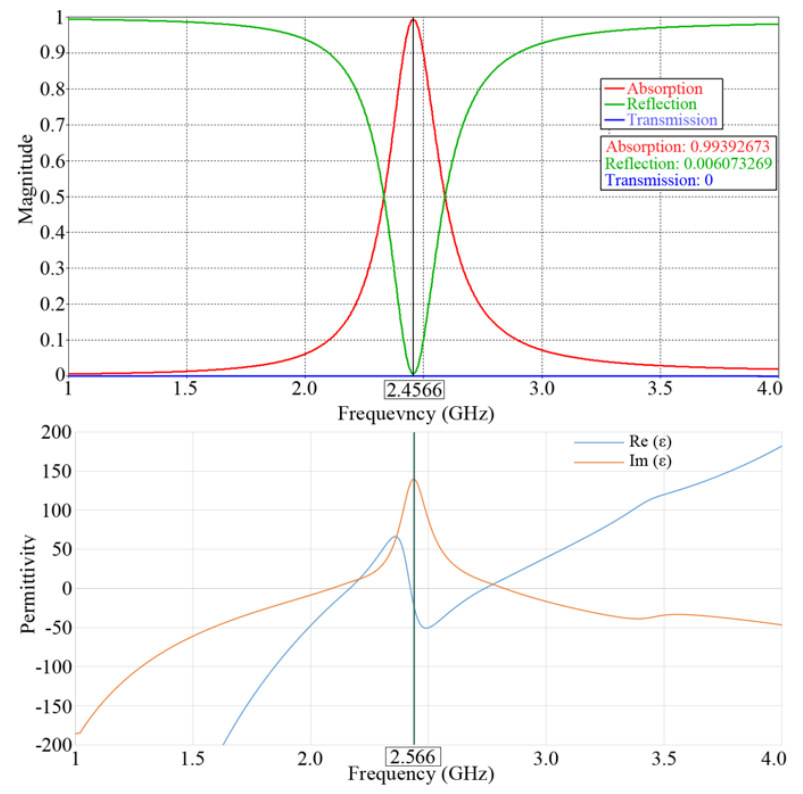

Figure 4 (a) The absorption, reflection and transmission characteristics of designed MTM structure and (b) the real and imaginary part of permittivity.

In the next phase, we have analyzed in the vicinity of a cylindrical human tissue model, as shown in Figure 5a. This human model consists of a $13 \mathrm{~mm}$ radius bone layer, a $20 \mathrm{~mm}$ radius muscle layer, a $5 \mathrm{~mm}$ radius fat layer, and a $2 \mathrm{~mm}$ radius skin layer. These tissues are located in the cylinder respectively and the total radius of the cylinder human model is $40 \mathrm{~mm}$. We show in Figure $5 \mathrm{~b}$ that the textile antenna is in direct contact with human body. This integrated system has given rise to a number of potential problems. In this context, we have realized the SAR analysis for wearable antenna. The wearable systems have leaded to exposure of the people to electromagnetic radiation by wearable equipment and then produced the biological effects towards the human body. The basic restrictions have been conducted to control the SAR towards the human body to minimize the potential health 
hazard. Therefore, we placed the EBG structure between the wearable monopole antenna and human body as shown in Figure 5c and applied bending to both of the structures.

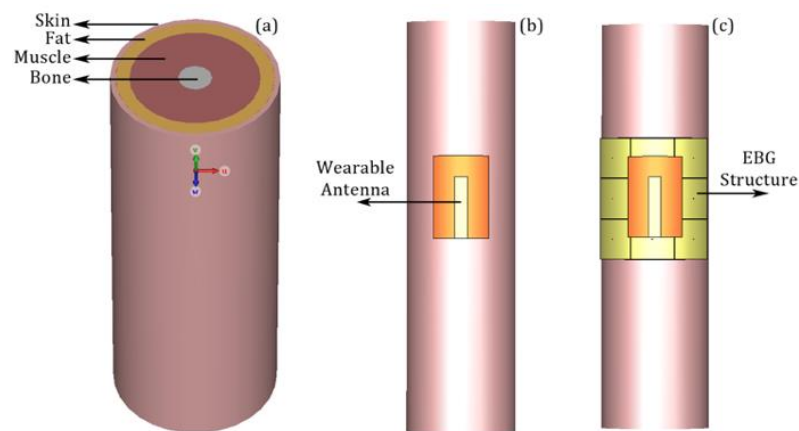

Figure 5 (a) Human body model, (b) A monopole antenna in direct contact with the human body, and (c)Integration of EBG structure between the antenna and the human body.

In the final stage, we carried out the SAR calculations of the MTM based wearable monopole antenna. The SAR results have been used for controlling the potential harmful effects on the human health. The SAR formula can be defined as:

$$
S A R=\frac{P}{\sigma}=\frac{\sigma E^{2}}{2 \rho}
$$

where $P$ is the power loss density, $\sigma$ is the tissue conductivity, $E$ is the electric filed amplitude in tissue, and $\rho$ is the density of tissue. Then, we obtained the SAR reduction factor (SRF) of proposed structures, which is defined as:

$$
S R F(\%)=\frac{S A R_{\text {antenna }}-S A R_{\text {antena }+E B G}}{S A R_{\text {antenna }}} \times 100
$$

We investigated the amount of EM wave absorbed in the human body. According to the analysis results of the proposed structures, the SAR value was obtained as 17.4 $\mathrm{W} / \mathrm{kg}$ when there is a direct contact between human body and monopole antenna as shown in Fig 6a. This value which is approximately the value of efficient antennas has detrimental effect on human body. If the EBG structure is used between human body and monopole antenna, the SAR value decreases to $0.329 \mathrm{~W} / \mathrm{kg}$ (Figure $6 \mathrm{~b})$. Since, this value is lower than the European standard $(2 \mathrm{~W} / \mathrm{kg})$, it can be said that the proposed structure is quite good. Later, we designed the $4 \times 3$ EBG structure and integrated the proposed monopole antenna and new EBG structure. We calculated the SAR value of this integrated structure. The SAR value of new integrated structure was obtained $0.241 \mathrm{~W} / \mathrm{kg}$ when $4 \times 3 \mathrm{EBG}$ structure was integrated to antenna (Figure 6c). According to these results, the proposed structures have considerably successful SRF values which are 98.1 and $98.6 \%$ for 0.329 and $0.241 \mathrm{~W} / \mathrm{kg}$ SAR values, respectively. It can be said that the proposed integrated structure has a quite good surface wave suppression feature. In addition, the other advantages of structure are low-cost and bendability. As a result, EBG based electrotextile antennas can be utilized in various applications where wearable antenna technologies are used. (a)

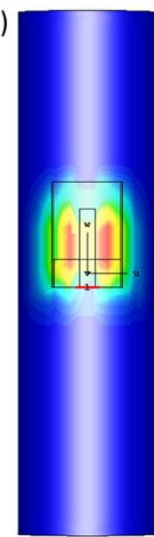

(b)

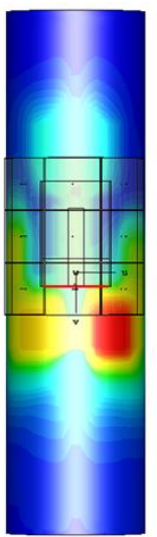

(c)

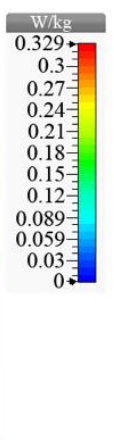

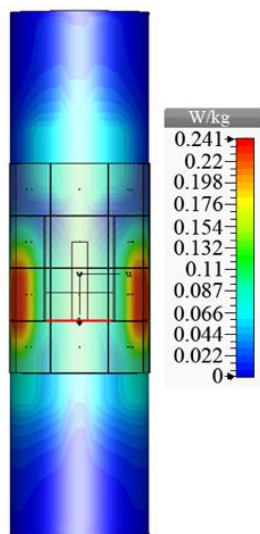

Figure 6 (a) SAR value obtained in direct contact, SAR value obtained when (b) $3 \times 3$ and (c) $4 \times 3$ unit cell EBG structure was placed between human body and antenna.

\section{Conclusion}

This study demonstrates an EBG structure based wearable monopole antenna that operates at $2.45 \mathrm{GHz}$ for wireless communication. Firstly, we designed the electro-textile based monopole antenna and simulated the reflection coefficients. The results obtained from the simulation show that monopole antenna reflects at a frequency of $2.45 \mathrm{GHz}$. Then, we analyzed the SAR value of antenna according to result of this frequency. Secondly, we designed the mushroom based EBG structure and integrated it to the antenna. Also, we analyzed the SAR value of the integrated structure. Wearable antenna directly mounted on the body gives $17.4 \mathrm{~W} / \mathrm{kg}$ SAR value taken over $10 \mathrm{~g}$ of tissue. This value is very high for European standard $(2 \mathrm{~W} / \mathrm{kg})$. To overcome this problem, we used the EBG structure and 
obtained integrated wearable antenna design. In this case, this new structure (3X3 unit cell) reduces the value of SAR to $0.329 \mathrm{~W} / \mathrm{kg}$. Similarly, the SAR value of antenna and $4 \times 3$ unit cell EBG structure was obtained as 0.241 $\mathrm{W} / \mathrm{kg}$. These are considerable values according to general SAR value standards. In addition, the proposed structures have 97.6 and $99.9 \%$ SRF values for $3 \times 3$ and $4 \times 3$ EBGs, respectively. These values are quite adequate for wearable antenna applications. Consequently, the proposed integrated antenna design can be applied to many areas such as military, health monitoring, and wireless communication.

\section{References}

1. Rais, N.H.M, Soh, P.J, Malek, F, Ahmad, S, Hashim, N.B.M, Hall P.S.A, Review of Wearable Antenna, Loughborough Antennas \& Propagation Conference, Loughborough, UK, 2009, pp 225-228.

2. Hall, P.S, Hao, Y, Antennas and propagation for body centric communications, First European Conference on Antennas and Propagation, Nice, France, 2006.

3. Linz, T, Simon, E.P, Walter, H, Modeling embroidered contacts for electronics in textiles, The Journal of the Textile Institute, Taylor \& Francis, 2011, 1-10

4. Soh, P.J, Vandenbosch, G.A.E, Ooi, S.L, Husna, M.R.N, Wearable dual-band Sierpinski fractal PIFA using conductive fabric, Electronics Letters, 2011, 47(6), 365-367.

5. Zhu, S, Langley, R, Dualband wearable textile antenna on an EBG substrate, IEEE Transactions on Antenna and Propagation, 2009, 57(4), 926-935.

6. Bai, Q, Langley, R, Wearable EBG antenna bending, Antennas and Propagation, EuCAP-2009, 3rd European Conference, Berlin, Germany, 2009, pp 182-185.

7. Sankaralingam, S, Gupta, B, Use of electro-textiles for development of wibro antennas, Progress in Electromagnetics Research C, 2010, 16, 183-193.

8. Osman, M.A.R, Rahim, M.K.A, Samsuri, NçA, Salim H.A.M, Ali, M.F, Embroidered fully textile wearable antenna for medica monitoring applications, Progress in Electromagnetics Research, $2011,117,321-337$

9. Mantash, M, Tarot, A.C, Collardey, S, Mahdjoubi, K, Investigation of flexible textile antennas and AMC reflectors, International Journal of Antennas and Propagation, 2012, 2012, 1-10.
10. Klemm, M, Troester, G, Textile UWB antennas for wireless body area networks, IEEE Transactions on Antennas and Propagation, 2006, 54(11), 3192-3197.

11. Salonen, $\mathrm{P}$, Keskialammi, M, Sydanheimo, L, A low cost $2.45 \mathrm{GHz}$ photonic band gap patch antenna for wearable system, IEE 11th Intnl. Conf. On Antennas \& Propagation (ICAP2001), Manchester, UK, 2001, pp 719- 723

12. Salonen, P.O, Yang, F, Rahmat-Samii and Kivikoski, M, WEBGAWearable Electromagnetic Band-Gap Antenna, IEEE Antennas \& Propagat. Int. Symposium, Sendai, Japan, 2004, pp 451-454.

13. Veselago, V.G, The electrodynamics of substances with simultaneously negative values of $\varepsilon$ and $\mu$, Soviet Physics USPEKHI, 1968, 10(4), 509-514

14. Dincer, F, Karaaslan, M, Colak, S, Tetik, E, Akgol, O, Altıntas, O, Sabah, C, Multi-band polarization independent cylindrical metamaterial absorber and sensor application, Modern Physics Letters B, 2016, 30(08), 1650095 .

15. Zhang, Y, Fiddy, M.A, Covered image of superlens, Progress in Electromagnetics Research, 2013, 136, 225-238.

16. Chen, $X$, Implicit boundary conditions in transformation-optics cloaking for electromagnetic waves, Progress in Electromagnetics Research, 2011, 121, 521-534.

17. Unal, E, Dincer, F, Tetik, E, Karaaslan, M, Bakir, M, Sabah, C, Tunable perfect metamaterial absorber design using the golden ratio and energy harvesting and sensor applications", Journal of Materials Science: Materials in Electronics, 2015, 26(12), 9735 9740

18. Salonen, $\mathrm{P}$, Rahmat-Samii, Y, Schaffrath, M, Kivikoski, M, Effect of Textile Materials on Wearable Antenna Performance: A Case Study of GPS Antennas, IEEE Antennas \& Propagat. Int. Symposium, Sendai, Japan, 2004, pp 459-462.

19. Tetik, E, D. Tetik, G., The Effect of a Metamaterial Based Wearable Microstrip Patch Antenna on Human Body, Canadian Journal of Physics, 2017, 95(13), 1292-1298.

20. Tronquo, A, Rogier, H, Hertleer, C, Langenhove, L.V, Applying textile materials for the design of antennas for wireless body area networks, Proceedings of the European Conference on Antennas and Propagation, Nice, France, 2006. 